\title{
Assignment of Brevibacterium stationis (ZoBell and Upham 1944) Breed 1953 to the genus Corynebacterium, as Corynebacterium stationis comb. nov., and emended description of the genus Corynebacterium to include isolates that can alkalinize citrate
}

Correspondence

Kathryn A. Bernard

Kathy_bernard@phac-aspc.gc.ca

\author{
Kathryn A. Bernard, ${ }^{1,2}$ Deborah Wiebe, ${ }^{1}$ Tamara Burdz, ${ }^{1}$ Aleisha Reimer, ${ }^{1}$ \\ Betty $\mathrm{Ng}^{1}$ Cathleen Singh, ${ }^{2}$ Samantha Schindle ${ }^{2}$ and Ana Luisa Pacheco ${ }^{2}$
'Special Bacteriology Section, National Microbiology Laboratory, Public Health Agency of Canada, Winnipeg, MB R3E 3R2, Canada \\ ${ }^{2}$ Department of Microbiology, University of Manitoba, Winnipeg, MB, Canada
}

Brevibacterium stationis was first described in 1944 as 'Achromobacter stationis' (ZoBell \& Upham, 1944) and was later assigned to the genus Brevibacterium (Breed, 1953). Placement of this species in the genus Brevibacterium has been questioned since at least 1972 (Yamada \& Komagata, 1972b), and the species was described by Jones \& Keddie (1986) as a species incertis sedis. Chemotaxonomic features of B. stationis ATCC $14403^{\mathrm{T}}$ include the presence of mesodiaminopimelic acid, cell-wall sugars arabinose and galactose, the presence of corynomycolates, menaquinone types $\mathrm{MK}-8\left(\mathrm{H}_{2}\right)$ and $\mathrm{MK}-9\left(\mathrm{H}_{2}\right)$ as sole respiratory quinones and cellular fatty acids of the straight-chain and monounsaturated types, rather than the branched-chain types associated with Brevibacterium, features actually consistent with the genus Corynebacterium (Jones \& Keddie, 1986). Similar phenetic and chemotaxonomic features had been reported for Brevibacterium ammoniagenes (Cooke \& Keith, 1927), which prompted its reassignment to the genus Corynebacterium (Collins,

\footnotetext{
Abbreviation: CFA, cellular fatty acid.
}

The GenBank/EMBL/DDBJ accession numbers for the sequences determined in this study are FJ172666 (strain NML 03-0173), FJ172667 (B. stationis ATCC 14403'), FJ172668 (NML 94-0424) and FJ648509 (C. ammoniagenes ATCC 6872) (16S rRNA gene) and FJ172669 (NML 03-0173), FJ172670 (NML 94-0424), FJ172671 (B. stationis ATCC $14403^{\top}$ ), FJ648510 (C. ammoniagenes ATCC 6872) and FJ648511 (C. ammoniagenes ATCC 6871 ${ }^{\top}$ ) (partial rpoB gene).
1987). Differentiation of B. stationis ATCC $14403^{\mathrm{T}}$ from phenotypically similar taxa has historically been difficult. In 1983, using comprehensive probabilistic methods to analyse a wide variety of microbial characteristics, this strain was assigned to cluster E-II, along with $C$. ammoniagenes strains ATCC $6871^{\mathrm{T}}\left(=\mathrm{DSM} 20306^{\mathrm{T}}\right)$, ATCC 15137 and IFO 12072 (=ATCC 6872) (Seiler, 1983). In 1993, B. stationis ATCC $14403^{\mathrm{T}}$ was assigned using phenetic-grouping analytical methods to ' $C$. ammoniagenes cluster 49', which included various reference $C$. ammoniagenes strains, including ATCC $6871^{\mathrm{T}}$ and ATCC 6872 (Kämpfer \& Seiler, 1993). C. ammoniagenes strains ATCC $6871^{\mathrm{T}}$ and ATCC 6872 had been compared with each other by DNA-DNA hybridization and found to be closely related but not identical, and so were thought possibly to be members of different taxon groups (Jones \& Keddie, 1986). All established reference strains of $B$. ammoniagenes which were not glutamic acid producers were transferred to C. ammoniagenes (Collins, 1987), including C. ammoniagenes ATCC 6872, which has been the subject of intense study in recent years with respect to various important industrial applications, including nucleoside and vitamin $\mathrm{B}_{12}$ production (Wang et al., 2007a, b).

In this study, two clinically derived isolates are reported that were most like members of the genus Corynebacterium except that they alkalinized citrate as a sole carbon source, a feature not described previously for any Corynebacterium 
species. Using $16 \mathrm{~S}$ rRNA and partial $r p o B$ gene sequencing, the isolates were found to be most closely related to $B$. stationis ATCC $14403^{\mathrm{T}}$ and otherwise were most closely related to $C$. ammoniagenes, among species in the genus Corynebacterium. Subsequently, biochemical, chemotaxonomic and genetic features of the clinical isolates as well as reference strains of $B$. stationis and C. ammoniagenes were studied to determine precise phylogenetic relationships and to address the long-standing recommendation that B. stationis should be transferred to Corynebacterium.

Isolates NML 94-0424 and NML 03-0173 (identifiers of the Canadian National Microbiology Laboratory, Winnipeg, $\mathrm{MB}$, Canada) were obtained from blood cultures from a 62 -year-old male with a chest infection and a 66-year-old female, but with no further clinical information being extant. They were originally identified as being most like Corynebacterium species but, by 16S rRNA gene sequencing, had $<98 \%$ identity with the closest relative C. ammoniagenes, and both strains alkalinized citrate. B. stationis ATCC $14403^{\mathrm{T}}$ and C. ammoniagenes strains ATCC $6871^{\mathrm{T}}$ and ATCC 6872 were acquired from the American Type Culture Collection (Manassas, VA, USA).

Clinical and reference strains were studied morphologically and biochemically tested using conventional (tube) sugars and substrates as outlined previously (Bernard et al., 2002a). In addition, API Coryne, API ZYM, API 20E and API 50CH strips were used and apiweb (https://apiweb. biomerieux.com) was queried as described by the manufacturer (bioMérieux) to see what identification would be provided based on the code generated by the API Coryne strip. For this study, Simmons' citrate was used to determine alkalinization of citrate (Weyant et al., 1996), but API $20 \mathrm{E}$ strips were also tested for utilization of citrate, one using a light and one a heavy bacterial suspension, and incubated as described by the manufacturer.

Antimicrobial susceptibility testing was performed by microbroth dilution according to methods recommended by the Clinical and Laboratory Standards Institute and interpretative criteria for Corynebacterium species (CLSI, 2006) using cation-adjusted Mueller-Hinton broth with $2.5 \%$ lysed horse blood and Sensititre STP5F and GPN3F plates (Trek Diagnostic). Antimicrobial agents tested included ampicillin, cefepime, cefotaxime, ceftriaxone, cefuroxime, chloramphenicol, ciprofloxacin, clindamycin, daptomycin, erythromycin, ertapenam, gatifloxacin, gentamicin, levofloxacin, linezolid, meropenem, moxifloxacin, penicillin, quinupristin/dalfopristin, rifampicin, telithromycin, tetracycline, tigecycline, trimethoprim/sulfamethoxazole and vancomycin.

Cellular fatty acid (CFA) composition analysis was done using the Sherlock system (MIDI) as outlined previously except that version 4.5 of the operating software was used (Bernard et al., 1991). CFAs were studied further using library generation system software (MIDI). Metabolic products were determined as described previously (Bernard et al., 2002b). Clinical isolate NML 94-0424 was also analysed for types and quantities of respiratory quinones, extracted as described by Karr et al. (1982) and analysed using an HP 1100 HPLC with UV detector and an in-house calibration mixture containing saturated and unsaturated menaquinones MK-6 to MK-10. Otherwise, descriptions of quinones and $\mathrm{G}+\mathrm{C}$ content from $B$. stationis and $C$. ammoniagenes reference strains were reported previously (Jones \& Keddie, 1986; Collins, 1987).

16S rRNA gene sequencing was done as outlined previously (Bernard et al., 2002b), yielding 1400-1500 bp, and partial sequencing (400-430 bp) of the $r p o B$ gene was performed as described by Khamis et al. (2004). 16S rRNA gene sequences were derived from this study or from GenBank, including accession no. AJ620367 from B. stationis LMG $21670^{\mathrm{T}}$. A reference sequence for C. ammoniagenes derived from CIP $101283^{\mathrm{T}}$, GenBank accession no. X84440, was used for comparative analysis. Sequences were aligned using CLUSTAL $\mathrm{W}$ and the relationship among aligned sequences was inferred using 1000 replications and neighbour-joining analysis software found in MEGA 4 (Kumar et al., 2008), with the scale shown representing percentage sequence divergence. Partial $r p o B$ sequences were analysed using neighbour-joining software in MEGA 4, and a sequence from a fragment of similar size ( $420 \mathrm{bp})$ from Corynebacterium tuberculostearicum CCUG $45418^{\mathrm{T}}$ served as an outgroup.

Strains NML 94-0424 and NML 03-0173, C. ammoniagenes ATCC 6872 and B. stationis ATCC $14403^{\mathrm{T}}$, collectively referred to here as the $B$. stationis-like group, were found to produce colonies that were $1 \mathrm{~mm}$ in diameter, raised and whitish at $24 \mathrm{~h}$, but yellowish or tan-pigmented after $48 \mathrm{~h}$ or more. All strains grew well within $24 \mathrm{~h}$ at $35{ }^{\circ} \mathrm{C}$. All were observed to have small, ovoid or medium-length, Gramstain-positive rod-shaped cells without spores that occurred singly, in pairs or in ' $\mathrm{V}$ ' forms and exhibited club shapes. No haemolysis was observed on sheep-blood agar (SBA). No strain demonstrated lipophilia. C. ammoniagenes ATCC $6871^{\mathrm{T}}$ produced grey-white colonies at $24 \mathrm{~h}$ or older and, by Gram stain, was similar to B. stationis ATCC $14403^{\mathrm{T}}$. Strains of both species grew well on SBA at $25{ }^{\circ} \mathrm{C}$ in air, at $35{ }^{\circ} \mathrm{C}$ in atmospheres of $5 \% \mathrm{CO}_{2}$ and air or microaerophilically and at $42{ }^{\circ} \mathrm{C}$ in air, but not at 50 or $60{ }^{\circ} \mathrm{C}$ or at $35{ }^{\circ} \mathrm{C}$ under strictly anaerobic conditions. All strains were catalase-positive and oxidase-negative. Biochemical results and enzymes detected are summarized in Table 1; most notably, all strains alkalinized citrate within $24-48 \mathrm{~h}$. Using the API 20E strip, citrate alkalinization was positive when a heavy inoculum was used, equivalent to a $5 \mathrm{McFarland}$ standard, but not when a light suspension was used. Citrate alkalinization has not been described previously for members of Corynebacterium sensu stricto (Collins \& Cummins, 1986) or for B. stationis or C. ammoniagenes (Jones \& Keddie, 1986; Collins, 1987). Using the API Coryne system, B. stationis ATCC $14403^{\mathrm{T}}$ and strains NML 94-0424 and NML 03-0173 generated a code of 3001304 and C. ammoniagenes strains ATCC $6871^{\mathrm{T}}$ and ATCC 6872 generated a code of 1001304 (that is, 
Table 1. Biochemical tests for $B$. stationis-like strains, C. ammoniagenes ATCC $6871^{\top}$ and phenotypically similar species arising from use of apiweb, based on API Coryne codes

Taxa: 1 , B. stationis ATCC $14403^{\mathrm{T}} ; 2$, C. ammoniagenes ATCC $6872 ; 3$, NML 94-0424; 4, NML 03-0173; 5, C. ammoniagenes ATCC 6871 ${ }^{\mathrm{T}} ; 6$, C. renale (usual source, bovines); 7, C. pseudotuberculosis (usual source, sheep). Data were obtained from this study and from Jones \& Keddie (1986), Collins (1987), Collins \& Cummins (1986) and Funke \& Bernard (2007). ND, No data available; +, positive using tube sugars within 6 days (the same substrates were weakly reactive for B. stationis and C. ammoniagenes strains using API $50 \mathrm{CH}$ or API Coryne panels); -, negative/not reactive; $d$, variable depending on the strain. All taxa were positive for fermentation of glucose and fructose and urease activity. All strains were negative for fermentation of xylose, mannitol, lactose, maltose, galactose, glycerol, glycogen, raffinose, salicin, trehalose and aesculin, gas from nitrate, nitrite reduction, indole production, methyl red/Voges-Proskauer reaction, gelatin hydrolysis, CAMP and CAMP inhibition (reverse CAMP), DNase activity, hydrolysis of casein and starch and lysine, arginine and ornithine decarboxylases. Enzymes from the API Coryne gallery that were not detected included pyrrolidonyl arylamidase, $\beta$-glucuronidase, $\beta$-galactosidase, $\alpha$-glucosidase and $N$-acetyl- $\beta$-glucosaminidase. Enzymes tested from the API ZYM panel that were found to be occasionally reactive were leucine arylamidase and esterase; all strains were non-reactive in the API ZYM panel for alkaline phosphatase, esterase lipase, lipase, valine arylamidase, cystine arylamidase, trypsin, $\alpha$-chymotrypsin, acid phosphatase, naphthol-AS-BI-phosphohydrolase, $\alpha$-galactosidase, $\beta$-galactosidase, $\beta$-glucuronidase, $N$-acetyl- $\beta$ glucosaminidase, $\alpha$-mannosidase and $\alpha$-fucosidase.

\begin{tabular}{|lccccccc|}
\hline Strain & $\mathbf{1}$ & $\mathbf{2}$ & $\mathbf{3}$ & $\mathbf{4}$ & $\mathbf{5}$ & $\mathbf{6}$ & $\mathbf{7}$ \\
\hline Pigmentation at $48 \mathrm{~h} \mathrm{~h}^{*}$ & $\mathrm{Y}$ & $\mathrm{Y}$ & $\mathrm{Y}$ & $\mathrm{Y}$ & $\mathrm{GW}$ & $\mathrm{Y}$ & $\mathrm{Y}$ \\
Fermentation of: & & & & & & & \\
$\quad$ Ribose & + & + & + & + & + & $\mathrm{ND}$ & $\mathrm{ND}$ \\
$\quad$ Mannose & + & + & + & + & - & + & + \\
Citrate alkalinization & + & + & + & + & + & - & - \\
Nitrate reduction & + & + & + & + & + & - & $\mathrm{d}$ \\
Tyrosine hydrolysis & + & + & + & + & + & - & - \\
Pyrazinamidase & + & - & + & + & - & + & + \\
CAMP inhibition & - & - & - & - & - & - & + \\
Presence of diphtheria tox & - & - & - & - & - & - & + \\
$\quad$ gene & & & & & & & \\
Cysteinase production & - & - & - & - & - & - & + \\
\hline
\end{tabular}

${ }^{\star} \mathrm{GW}$, Grey-white; Y, yellowish.

pyrazinamidase was not detected), which, upon querying the apiweb database, related best to poor levels of confidence for the Corynebacterium renale group or Corynebacterium pseudotuberculosis, respectively. By either conventional tube substrates and/or using an API Coryne or API 50CH strip, both C. ammoniagenes ATCC $6871^{\mathrm{T}}$ and the $B$. stationis-like strains were slowly or weakly reactive with glucose, fructose and ribose, reduced nitrate, produced urease and hydrolysed tyrosine. B. stationis ATCC $14403^{\mathrm{T}}$ did not ferment CHO tube glucose, as described previously (Yamada \& Komagata, 1972a), but was reactive with glucose using the API Coryne and API $50 \mathrm{CH}$ panels. Historically, strains from both species have been found to hydrolyse hippurate (Jones \& Keddie, 1986). Most strains were weakly reactive with fucose substrate found in the API 50CH strip, also described previously for C. ammoniagenes (Kämpfer \& Seiler, 1993). The $B$. stationis-like strains, but not C. ammoniagenes ATCC $6871^{\mathrm{T}}$, fermented mannose weakly or slowly, unlike results found by ZoBell \& Upham (1944) but as cited later by Jones \& Keddie (1986). Previously described fermentation of sucrose, maltose and trehalose by $B$. stationis-like strains or C. ammoniagenes ATCC $6871^{\mathrm{T}}$ (Yamada \& Komagata, 1972a) was not observed here. Pyrazinamidase was reactive with three out of four B. stationis-like strains but was not detected for C. ammoniagenes ATCC $6871^{\mathrm{T}}$. Otherwise, these strains were non-reactive for detection of enzymes using the API ZYM panel, except for weak reactivity of C. ammoniagenes ATCC $6871^{\mathrm{T}}$ and ATCC 6872 for leucine arylamidase and B. stationis ATCC $14403^{\mathrm{T}}$ for esterase.

B. stationis ATCC $14403^{\mathrm{T}}$, strain NML 94-0424 and C. ammoniagenes ATCC 6872 were considered sensitive to all antimicrobials that have CLSI interpretative criteria. NML 03-0173 was observed to be resistant to erythromycin $\left(\mathrm{MIC}>4 \mu \mathrm{g} \mathrm{ml}^{-1}\right.$ ). C. ammoniagenes ATCC $6871^{\mathrm{T}}$ was found to be sensitive to all antimicrobials except erythromycin ( $\mathrm{MIC}>4 \mu \mathrm{g} \mathrm{ml}{ }^{-1}$ ) and clindamycin (MIC $>2 \mu \mathrm{g}$ $\mathrm{ml}^{-1}$ ) (resistant), as well as having MICs of $2 \mu \mathrm{g} \mathrm{ml}$ (intermediate susceptibility) for cefotaxime and ceftriaxone.

CFAs were consistent with those determined previously for both $C$. ammoniagenes and B. stationis and with those of the genus Corynebacterium (Table 2) (Bernard et al., 1991). Based on this analysis, CFAs were deemed to be quantitatively and qualitatively indistinguishable between C. ammoniagenes ATCC $6871^{\mathrm{T}}$ and the B. stationis-like group. These CFAs were qualitatively unlike those described for members of Brevibacterium sensu stricto, where the majority of CFAs are of the branched-chain types (Jones \& Keddie, 1986; Gruner et al., 1994). Metabolic products found for B. stationis-like strains and C. ammoniagenes ATCC $6871^{\mathrm{T}}$ were similar, with small volumes of lactic and succinic acids but not propionic acid being detected; the latter is only observed for about $25-30 \%$ of all Corynebacterium species (Bernard et al., 2002a). Respiratory quinones for B. stationis ATCC $14403^{\mathrm{T}}$ were described as comprising roughly equal amounts of $\mathrm{MK}$ $8\left(\mathrm{H}_{2}\right)$ and MK-9 $\left(\mathrm{H}_{2}\right)$ (Collins, 1987), and similar menaquinones were detected here for NML 94-0424 (data not shown), in contrast to members of Brevibacterium sensu stricto, which have $\mathrm{MK}-8\left(\mathrm{H}_{2}\right)$ as the sole menaquinone (Jones \& Keddie, 1986).

By 16S rRNA gene sequencing analysis, NML 94-0424, NML03-0173 and C. ammoniagenes ATCC 6872 had 99.2, 99.6 and $99.8 \%$ identity with B. stationis ATCC $14403^{\mathrm{T}}$, respectively; these four strains showed 98.1, 98.0, 98.0 and $97.9 \% 16 \mathrm{~S}$ rRNA gene sequence identity, respectively, to 
Table 2. CFA composition of strains of the $B$. stationis-like group and C. ammoniagenes sensu stricto

Values represent percentages of total fatty acids detected rounded to nearest integer; ND, not detected. TBSA, Tuberculostearic acid (10methyl $\mathrm{C}_{18: 0}$ ). Strains of the $B$. stationis-like group also contained trace amounts of $\mathrm{C}_{12: 0}$ and all strains contained trace amounts of $\mathrm{C}_{16: 1} \omega 7 c$ (part of summed feature 3 in the MIDI system).

\begin{tabular}{|c|c|c|}
\hline Fatty acid & $\begin{array}{l}\text { B. stationis-like strains } \\
\qquad(n=4)\end{array}$ & $\begin{array}{l}\text { C. ammoniagenes } \\
\text { ATCC } 6871^{\mathrm{T}}\end{array}$ \\
\hline $\mathrm{C}_{14: 0}$ & 2 & 1 \\
\hline $\mathrm{C}_{16: 1} \omega 9 c$ & 1 & 1 \\
\hline$C_{16: 0}$ & 41 & 32 \\
\hline $\mathrm{C}_{17: 1} \omega 9 c$ & 4 & 9 \\
\hline $\mathrm{C}_{17: 1} \omega 8 c$ & 1 & $\mathrm{ND}$ \\
\hline $\mathrm{C}_{17: 0}$ & 2 & 4 \\
\hline $\mathrm{C}_{18: 1} \omega 9 c$ & 37 & 41 \\
\hline $\mathrm{C}_{18: 1} \omega 7 c$ & 2 & $\mathrm{ND}$ \\
\hline $\mathrm{C}_{18: 0}$ & 7 & 7 \\
\hline TBSA & 2 & 2 \\
\hline
\end{tabular}

C. ammoniagenes ATCC $6871^{\mathrm{T}}$ (Fig. 1). Using criteria described by Stackebrandt \& Ebers (2006), strains with $98.8 \%$ identity or more can be considered members of the same taxon group. These relationships were corroborated by partial $r p o B$ sequence analysis, where NML 94-0424, NML 03-0173 and C. ammoniagenes ATCC 6872 had 99.8, 98.6 and $99.5 \%$ identity, respectively, to B. stationis ATCC $14403^{\mathrm{T}}$, but $\sim 90 \%$ identity to C. ammoniagenes ATCC $6871^{\mathrm{T}}$ (Fig. 2). By partial $r p o B$ gene sequence analysis, strains that demonstrate $\geqslant 95 \%$ identity are considered members of the same taxon group (Khamis et al., 2005).

Based on these studies, we conclude that B. stationis should be transferred to the genus Corynebacterium, as Corynebacterium stationis comb. nov., and that ATCC
6872 be reassigned from C. ammoniagenes to be included in C. stationis. Because these strains alkalinize citrate, we propose that the description of the genus Corynebacterium be amended to include citrate-positive strains. Although the phenotypic tests used were not an exhaustive list, our results suggest that discrimination between $C$. stationis and C. ammoniagenes sensu stricto will be difficult without genetic characterization. Data from this study using phylogenetically characterized strains suggested that C. stationis strains differed from $C$. ammoniagenes by pigment (yellow or yellowish colonies, not grey-white after $48 \mathrm{~h}$ ), by fermentation of mannose and by production of pyrazinamidase by most strains. Discrimination of both species from the taxa suggested by apiweb using API Coryne strips, i.e. C. renale and C. pseudotuberculosis, may be done using tests shown in Table 1.

\section{Emended description of the genus Corynebacterium Lehmann and Neumann 1896}

Species in the genus exhibit the properties described by Collins \& Cummins (1986); in addition, strains of some species also alkalinize citrate.

\section{Description of Corynebacterium stationis (ZoBell and Upham 1944) comb. nov.}

Corynebacterium stationis (sta.ti.o' nis. L. gen. n. stationis of a fixed position).

Basonym: Brevibacterium stationis (ZoBell and Upham 1944) Breed 1953.

Other synonym: 'Achromobacter stationis' ZoBell and Upham 1944.

This description is based on the description of Brevibacterium stationis given by Jones \& Keddie (1986) and from

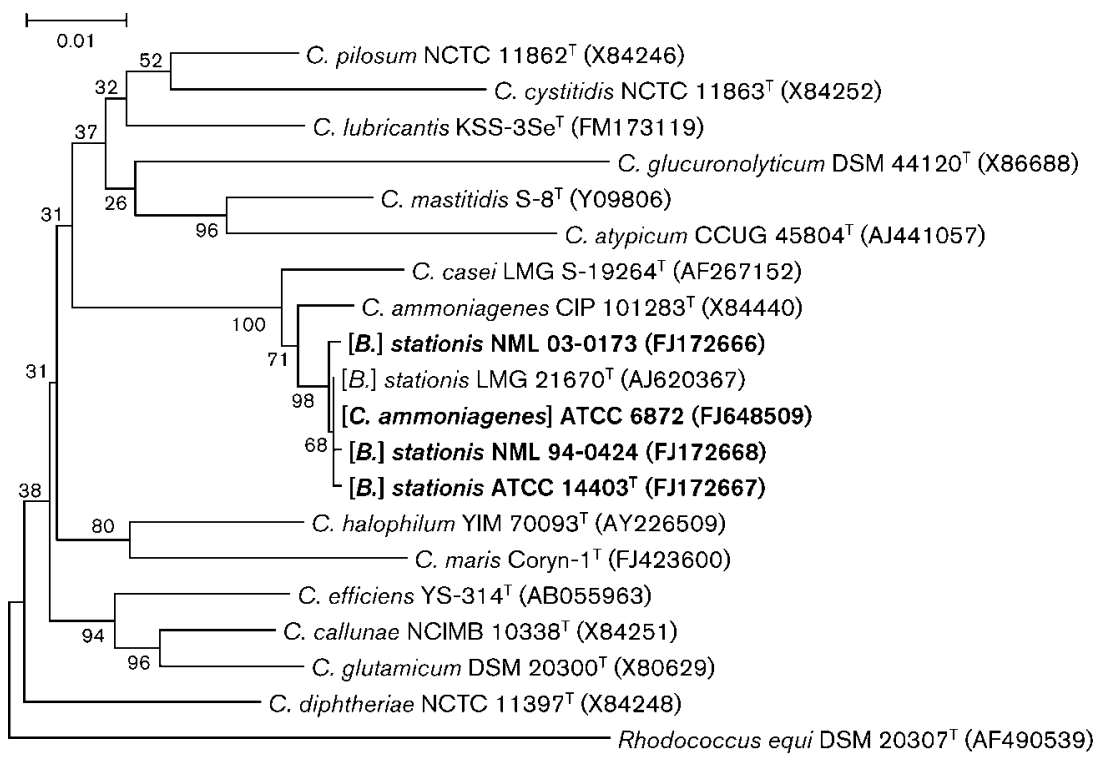

Fig. 1. Relationship of nearly full-length $16 \mathrm{~S}$ rRNA gene sequences from strains of Corynebacterium stationis comb. nov. and phylogenetically closely related Corynebacterium species, with Corynebacterium diphtheriae NCTC $11397^{\top}$ and Rhodococcus equi DSM $20307^{\top}$ as near and far outgroups, respectively. The tree was generated by the neighbour-joining method. Sequences determined in this study are highlighted in bold. Bar, 0.01 substitutions per nucleotide position. 


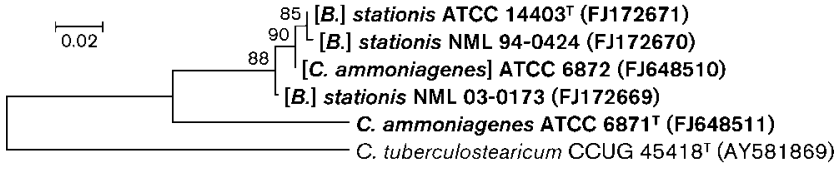

Fig. 2. Relationship of partial $r p o B$ gene sequences from strains of Corynebacterium stationis comb. nov. and phylogenetically closely related C. ammoniagenes, with C. tuberculostearicum CCUG $45418^{\top}$ as an unrelated outgroup. The tree was generated by the neighbour-joining method. Sequences determined in this study are highlighted in bold. Bar, 0.02 substitutions per nucleotide position.

observations in this study for strains ATCC $14403^{\mathrm{T}}$ and ATCC 6872 and two human blood-culture isolates. Grampositive, asporogenic, short rods, $0.6-1 \mu \mathrm{m}$ in diameter, occur singly, in pairs and in ' $\mathrm{V}$ ' forms and can be club shaped. Non-motile. Not acid-fast. Colonies on blood agar after $24 \mathrm{~h}$ are grey-white but become yellowish with age, about $1 \mathrm{~mm}$ in diameter and raised, with no haemolysis observed. Facultatively anaerobic, but grows better under aerobic conditions. Poor or no growth under strictly anaerobic conditions. Grows at 25,35 and $42{ }^{\circ} \mathrm{C}$ in air. Not lipophilic. Catalase-positive and oxidase-negative. Acid is produced, albeit slowly, from glucose, fructose and ribose. Fucose found in the API $50 \mathrm{CH}$ gallery is also weakly reactive. Weakly reactive for mannose. Xylose, mannitol, lactose, sucrose, maltose, galactose, glycerol, glycogen, raffinose, salicin and trehalose are not reactive. Triple-sugar iron remains neutral or alkaline or neutral. Grows in the presence of $6-10 \% \mathrm{NaCl}$. Urease is produced. Nitrate is reduced to nitrite but nitrite is not reduced to nitrogen using either conventional or API Coryne panel methods. Simmons' citrate is alkalinized. Tyrosine is hydrolysed but gelatin, aesculin, casein and starch are not. Not reactive in tests for lysine, arginine or ornithine decarboxylases. Christie-Atkins-Munch-Petersen (CAMP) and CAMP-inhibition reactions are not observed. DNase and indole are not produced. Pyrazinamidase may be produced, but otherwise most enzymes of the API ZYM panel are not detected. Strains are generally susceptible to a wide variety of antimicrobials. The cell-wall peptidoglycan has meso-diaminopimelic acid as the major diamino acid. Cell-wall sugars are arabinose and galactose. Mycolates are present. Menaquinones are the sole respiratory quinones, MK-8 $\left(\mathrm{H}_{2}\right)$ and MK-9 $\left(\mathrm{H}_{2}\right)$ being detected. CFAs are of the saturated and monounsaturated types and tuberculostearic acid is detected. The DNA G $+\mathrm{C}$ content for the type strain is $53.9 \mathrm{~mol} \%$ ( $T_{\mathrm{m}}$ method). Members of the species may be discriminated from other Corynebacterium species by observation of the alkalinization of citrate and other described reactions, and by $16 \mathrm{~S}$ rRNA and $r p o B$ gene sequencing.

The type strain, ATCC $14403^{\mathrm{T}}=$ CCUG $43497^{\mathrm{T}}=\mathrm{CIP}$ $104228^{\mathrm{T}}=\mathrm{DSM} 20302^{\mathrm{T}}=$ NBRC $12144^{\mathrm{T}}=\mathrm{JCM} 11611^{\mathrm{T}}$ $=\mathrm{VKM} \mathrm{B}-1228^{\mathrm{T}}$, was isolated from seawater. Strain ATCC 6872, previously assigned to $C$. ammoniagenes, was isolated from human infant stools and strains NML 94-0424 and NML 03-0173 were recovered from human blood cultures.

\section{Acknowledgements}

The technical assistance of Leanne de Winter, Cindy Munro and Matthew Walker is gratefully acknowledged.

\section{References}

Bernard, K. A., Bellefeuille, M. \& Ewan, E. P. (1991). Cellular fatty acid composition as an adjunct to the identification of asporogenous, aerobic gram-positive rods. J Clin Microbiol 29, 83-89.

Bernard, K. A., Munro, C., Wiebe, D. \& Ongsansoy, E. (2002a). Characteristics of rare or recently-described Corynebacterium species recovered from human clinical material in Canada. J Clin Microbiol 40, 4375-4381.

Bernard, K. A., Shuttleworth, L., Munro, C., Forbes-Faulkner, J. C., Pitt, D., Norton, J. H. \& Thomas, A. D. (2002b). Propionibacterium australiense sp. nov. derived from granulomatous bovine lesions. Anaerobe 8, 41-47.

Breed, R. S. (1953). The Brevibacteriaceae fam. nov. of order Eubacteriales. Rias Commun VI Congr Int Microbiol Roma 1, 13-14.

CLSI (2006). Methods for antimicrobial dilution and disk susceptibility testing of infrequently isolated or fastidious bacteria. Approved guideline M45-A. Wayne, PA: Clinical and Laboratory Standards Institute.

Collins, M. D. (1987). Transfer of Brevibacterium ammoniagenes (Cooke and Keith) to the genus Corynebacterium as Corynebacterium ammoniagenes comb. nov. Int J Syst Bacteriol 37, 442-443.

Collins, M. D. \& Cummins, C. S. (1986). Genus Corynebacterium Lehmann and Neumann 1896, 350 ${ }^{\mathrm{AL}}$. In Bergey's Manual of Systematic Bacteriology, vol. 2, pp. 1266-1276. Edited by P. H. A. Sneath, N. S. Mair, M. E. Sharpe \& J. G. Holt. Baltimore: Williams \& Wilkins.

Cooke, J. V. \& Keith, H. R. (1927). A type of urea-splitting bacterium found in the human intestinal tract. J Bacteriol 13, 315-319.

Funke, G. \& Bernard, K. A. (2007). Coryneform Gram-positive rods. In Manual of Clinical Microbiology, 9th edn, pp. 485-514. Edited by P. R. Murray, E. J. Baron, J. H. Jorgensen, M. L. Landry \& M. A. Pfaller. Washington, DC: American Society for Microbiology.

Gruner, E., Steigerwalt, A. J., Hollis, D. G., Weyant, R. S., Weaver, R. E., Moss, C. W., Daneshvar, M., Brown, J. M. \& Brenner, D. J. (1994). Human infections caused by Brevibacterium casei, formerly CDC groups B-1 and B-3. J Clin Microbiol 32, 1511-1518.

Jones, D. \& Keddie, R. M. (1986). Genus Brevibacterium Breed 1953, $13^{\mathrm{AL}}$ emend. Collins et al. 1980. In Bergey's Manual of Systematic Bacteriology, vol. 2, pp. 1301-1313. Edited by P. H. A. Sneath, N. S. Mair, M. E. Sharpe \& J. G. Holt. Baltimore: Williams \& Wilkins.

Kämpfer, P. \& Seiler, H. (1993). Probabilistic identification of coryneform bacteria. J Appl Microbiol 39, 215-236.

Karr, D. E., Bibb, W. F. \& Moss, C. W. (1982). Isoprenoid quinones of the genus Legionella. J Clin Microbiol 15, 1044-1048.

Khamis, A., Raoult, D. \& La Scola, B. (2004). rpoB gene sequencing for identification of Corynebacterium species. J Clin Microbiol 42, 3925-3931.

Khamis, A., Raoult, D. \& La Scola, B. (2005). Comparison between $r p o B$ and 16S rRNA gene sequencing for molecular identification of 168 clinical isolates of Corynebacterium. J Clin Microbiol 43, 19341936. 
Kumar, S., Nei, M., Dudley, J. \& Tamura, K. (2008). MEGA: a biologistcentric software for evolutionary analysis of DNA and protein sequences. Brief Bioinform 9, 299-306.

Lehmann, K. B. \& Neumann, R. (1896). Atlas und Grundriss der Bakteriologie und Lehrbuch der speciellen bakteriologischen Diagnostik. München: J. F. Lehmann (in German).

Seiler, H. (1983). Identification key for coryneform bacteria derived by numerical taxonomic studies. J Gen Microbiol 129, 1433-1471.

Stackebrandt, E. \& Ebers, J. (2006). Taxonomic parameters revisited: tarnished gold standards. Microbiol Today 33, 152-155.

Wang, X., Ma, C., Wang, X. \& Xu, P. (2007a). Orotate phosphoribosyltransferase from Corynebacterium ammoniagenes lacking a conserved lysine. J Bacteriol 189, 9030-9036.

Wang, X., Wang, X., Yin, M., Xiao, Z., Ma, C., Lin, Z., Wang, P. G. \& $\mathrm{Xu}$, P. (2007b). Production of uridine $5^{\prime}$-monophosphate by
Corynebacterium ammoniagenes ATCC 6872 using a statistically improved biocatalytic process. Appl Microbiol Biotechnol 76, 321-328.

Weyant, R. S., Moss, C. W., Weaver, R. E., Hollis, D. G., Jordan, J. G., Cook, E. C. \& Daneshvar, M. I. (1996). Identification of Unusual Pathogenic Gram-Negative Aerobic and Facultatively Anaerobic Bacteria, 2nd edn. Baltimore: Williams \& Wilkins.

Yamada, K. \& Komagata, K. (1972a). Taxonomic studies on coryneform bacteria. IV. Morphological, cultural, biochemical, and physiological characteristics. J Gen Appl Microbiol 18, 399-416.

Yamada, K. \& Komagata, K. (1972b). Taxonomic studies on coryneform bacteria. V. Classification of coryneform bacteria. J Gen Appl Microbiol 18, 417-431.

ZoBell, C. E. \& Upham, H. C. (1944). A list of marine bacteria including descriptions of sixty new species. Bull Scripps Inst Oceanogr 5, 239-292. 